\title{
A Gradient Harmonic Grammar Account of Nasals in Extended Phonological Words*
}

\author{
Anthi Revithiadou \\ Aristotle University of Thessaloniki \\ revith@lit.auth.gr \\ Giorgos Markopoulos \\ University of the Aegean \\ g.markopoulos@aegean.gr
}

Received: September 9, 2020

Accepted: June 29, 2021

\begin{abstract}
The article aims at contributing to the long-standing research on the prosodic organization of linguistic elements and the criteria used for identifying prosodic structures. Our focus is on final coronal nasals in function words in Greek and the variability in their patterns of realization before lexical words. Certain nasals coalesce before stops and delete before fricatives, whereas others do not. We propose that this split in the behavior of nasals does not pertain to item-specific prosody because the relevant strings are uniformly prosodified into an extended phonological word (Itô $\&$ Mester 2007, 2009). It rather stems from the contrastive activity level of nasals in underlying forms in the spirit of Smolensky \& Goldrick's (2016) Gradient Symbolic Representations; nasals with lower activity coalesce and delete in the respective phonological environments, whereas those with higher activity do not. We show that the proposed analysis captures certain gradient effects that alternative analyses cannot account for.
\end{abstract}

Keywords: Gradient Symbolic Representations; Gradient Harmonic Grammar; Greek; extended / maximal phonological word; nasal coalescence; post-nasal voicing

Resum. Una aproximació des de la gramàtica harmònica gradient a les nasals en paraules fonològiques recursives

Aquest article pretén contribuir a la investigació sobre l'organització prosòdica dels elements lingüístics i els criteris que es fan servir per identificar les estructures prosòdiques. Ens centrem en l'estudi de les nasals coronals finals en paraules funcionals en grec i la seva variabilitat en els patrons de realització davant de paraules lèxiques. Algunes nasals pateixen un procés de coalescència davant d'oclusives i s'elideixen davant de fricatives, mentre que d'altres no ho fan. Proposem que aquest doble comportament observat en les nasals no pertany a principis prosòdics dependents dels ítems en qüestió perquè totes aquestes estructures es prosodifiquen en una paraula fonològica estesa (recursiva) (Itô \& Mester 2007, 2009). Proposem que la divergència es deu a

* We wish to thank the audiences of SPIPS (University of Tromsø, 19-20 September 2019) and Recursivity in Phonology Below and Above the Word (Universitat Autònoma de Barcelona, 21-22 November 2019) for feedback and stimulating discussion. The article has also benefited greatly from insightful comments and suggestions by an anonymous reviewer. All errors are of course our own. 
nivells d'activitat diferents associats a les formes subjacents de les nasals, seguint la teoria de les representacions simbòliques gradients de Smolensky \& Goldrick (2016); les nasals associades amb un nivell baix d'activitat pateixen coalescència i s'elideixen en el context fonològic respectiu; mentre que les nasals amb un nivell d'activitat més alt no ho fan. Mostrem que l'anàlisi proposada captura certs efectes gradients que anàlisis alternatives no poden explicar.

Paraules clau: representacions simbòliques gradients; gramàtica harmònica gradient; grec; mot fonològic màxim; coalescència nasal; sonorització postnasal

\begin{tabular}{|c|c|}
\hline \multicolumn{2}{|c|}{ Table of Contents } \\
\hline 1. Introduction & $\begin{array}{l}\text { 4. A Gradient Harmonic Grammar } \\
\text { account of flimsy and stable /n/ }\end{array}$ \\
\hline involving nasals in constructions & 5. Exploring some alternatives \\
\hline with function words & 6. Conclusions \\
\hline $\begin{array}{r}\text { The prosodic structure of function } \\
\text { words }\end{array}$ & References \\
\hline
\end{tabular}

\section{Introduction}

There is a long debate in phonological theory on the prosodic organization of elements above and including the phonological word (PW / $\omega$ ) (see, e.g., Nespor \& Vogel 1986; Selkirk 1995, 2000; Vigário 2010). The "constituenthood" of a PW is typically identified on the basis of phonological (e.g., Booij 1995, 1996; Peperkamp 1997; Vigário 2003) and/or syntactic criteria (e.g., Selkirk 1995; Kabak \& Revithiadou 2009) that usually provide evidence for the presence of a prosodic boundary separating the unit in question from the rest of the structure. Here we concur with previous research that indeed both the phonology-morphosyntax interface and the phonology proper offer valuable information for identifying PW boundaries. However, we draw attention to cases in which, despite the existence of overwhelming phonological and/or syntactic evidence in support of a particular prosodic structure, certain outputs do not display the expected phonological behavior. More specifically, we examine nasal-voiceless stop (NÇ) sequences in constructions with function words (clitics, particles, complementizers, determiners) in a northern variety of Standard Greek. These sequences are of interest because in some cases post-nasal voicing with simultaneous coalescence of the nasal to the stop takes place, whereas in others the NÇ sequence is tolerated. The data in (1) illustrate each pattern:

$$
\begin{aligned}
& \text { a. /t-on }{ }^{1} \quad \text { pist-o/ } \\
& \text { the-M.SG.ACC believer-M.SG.ACC } \\
& \text { 'the (male) believer' }
\end{aligned}
$$

1. The SG.ACC $(\tau o v)$ and PL.GEN $(\tau \omega v)$ determiners are homophonous but orthographically distinct. 


b. /t-on $\quad$ pist-on/
the-PL.GEN believer-PL.GEN
'of the believers'

The blocking of coalescence and post-nasal voicing may be attributed to the presence of an intermediary prosodic word boundary in (1b), which is not present in (1a). As a result, the plural genitive form of the definite determiner cannot phonologically interact with the noun simply because it falls outside the PW the noun belongs to. Under this scenario, the less cohesive determiner, i.e. the exponent of the PL.GEN, may be argued to be prespecified with a left PW-boundary, i.e., $t-o n_{\text {PL.GEN }}\left[{ }_{\omega}\right.$, which prevents it from phonologically interacting with its host. On the other hand, the homophonous function word that realizes the SG.ACC form of the determiner would have to lack such a prosodic specification, and thus be free to incorporate into the $\mathrm{PW}$ of the following noun.

In this article, however, we propose an alternative account, according to which the prosodic structure of function word-plus-lexical word strings is argued, on the basis of phonological and syntactic evidence, to be the same in both (1a) and (1b), namely the extended phonological word, in the spirit of Itô \& Mester's (2007, 2009 et seq.) projection adjunction approach. Moreover, we posit that the difference in the behavior of the coronal nasals in examples like the ones in (1) reflects the difference in the robustness of the nasal: the $/ \mathrm{n} /$ in the SG.ACC form $t$-on (1a) that coalesces is considered to be less strong compared to the $/ \mathrm{n} /$ in the PL.GEN form $t$-on (1b). Within Smolensky \& Goldrick's (2016) Gradient Symbolic Representations theory, the inherent strength of a segment is formally expressed as activity level, which is realized with a specific numerical value (ranging from 0 to 1 ): the higher the activity value, the stronger the segment. The gradient activity values assigned to the coronal nasals of function words become crucially relevant to phonological computation because they interfere with post-nasal voicing and nasal coalescence, yielding different outputs, even within the same prosodic constituent. To be more precise, we propose a treatment of lexical variability in terms of an analysis that employs phonological representations with gradiently active segments, and not in terms of lexically-specific differences in the mapping from morphosyntactic to prosodic structure (see also Hsu 2019). These gradient effects are couched within the framework of Gradient Harmonic Grammar (Smolensky \& Goldrick 2016) where constraint weights and contrastive activity contribute jointly to the harmony of output forms.

The remainder of the article is organized as follows. In Section 2 we present data that illustrate the phonological behavior of coronal nasals of function words in various morphosyntactic environments. In Section 3 we provide phonological and morphosyntactic argumentation to establish that function words in Greek are prosodically adjoined to the PW of their host. In Section 4 we build a Gradient Harmonic Grammar analysis according to which the variable behavior of certain nasals results from the interaction of constraint weights with their different underlying activities. In Section 5 we briefly discuss alternatives to our analysis and in Section 6 we conclude the article. 


\section{Phonological processes involving nasals in constructions with function words}

Standard Greek does not allow NC sequences within the PW; the illegitimate sequence is resolved via voicing of the post-nasal stop. In certain varieties of Greek, especially in the north (e.g., Thessaloniki), the nasal coalesces with the following stop into a voiced consonant preceded by nasal murmur $\left[{ }^{\mathrm{m}} \mathrm{b}{ }^{\mathrm{n}} \mathrm{d}{ }^{\mathrm{n}} \mathrm{g}\right]$ (Kong et al. 2007). Yet, in other varieties, the nasal deletes after opaquely voicing the following stop (e.g., Athenian Greek; see Nespor \& Vogel 1986; Arvaniti \& Joseph 1999 ,

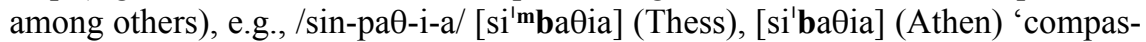
sion'; /sin-tak-s-i/ ['sin'daksi] (Thess), ['sidaksi] (Athen) 'syntax'. Interestingly, there is no interaction between nasals and fricatives within the word, e.g. /an $\theta$ os/ ['anӨos] 'flower'.

Although within the PW NC sequences are obligatorily resolved, a great deal of variation is attested across word boundaries. More specifically, one finds environments where $\mathrm{NC}$ s sequences are faithfully realized and environments where both post-nasal stop voicing (PNV) and nasal-stop coalescence (NasCoal) apply (henceforth PNV/NasCoal). We begin by reviewing faithful realizations, where PNV/NasCoal are blocked between a complementizer and a verb (2) and between a determiner and the following noun (3):

(2) Complementizer - verb

/an pist-ev-is/
COMP believe-vBLz-2sG
'if you believe'

[an pi'stevis]

(3) Determiner ${ }_{P L . G E N}-$ noun

$\begin{array}{ll}\text { /t-on } & \text { pist-on/ } \\ \text { the-PL.GEN } & \text { believer-PL.GEN }\end{array}$

'of the believers'

PNV/NasCoal appear to be blocked when the PL.GEN exponent /on/ is present in a structure, as further confirmed by examples such as (4), where a noun in PL.GEN form is followed by a possessive clitic. Blocking of coalescence in this case is particularly odd, especially if we take into consideration that enclitics incorporate into a single PW with their host, and post-nasal voicing is compulsory in this domain, e.g. /pan-e ton/ ${ }_{\omega}\left[{ }^{\prime} \mathrm{pa}^{\mathrm{n}} \mathrm{don}\right]$ 'take-2sG.IMP him', cf. /sin-tak-s-i/ ${ }_{\omega}\left[{ }^{[} \mathrm{si}^{\mathrm{n}}\right.$ daksi] 'syntax' (Revithiadou \& Spyropoulos 2008).

(4) Noun PL.GEN $_{\text {- clitic constructions }}$

/pist-on tus/ [pi'ston tus]

believer-PL.GEN POSS.3PL

'of their believers'

On the other hand, PNV/NasCoal apply in contexts where the accusative singular form of the determiner occurs, as shown in (5). 
(5) Determiner ${ }_{S G . A C C}-$ noun

/t-on [to mbi'sto]
the-M.SG.ACC believer-M.SG.ACC
'the (male) believer'

Both processes are equally enforced between the SG.ACC form of the pronominal clitic and the following noun or the negation particle /ðen/ and the following verb:

(6) Pron.clitic ${ }_{S G . A C C}-$ verb

/t-on [to mbi'stevis]

CL.3-M.SG.ACC believe-VBLZ-2SG

'you believe him'

(7) Negation marker/ðen/-verb

/ðen pist-ev-is/

NEG believe-VBLZ-2SG

[,ðe mbi'stevis]

'you do not believe'

Oddly enough, the other allomorph of negation, namely $/ \mathrm{min} /$, shows variation allowing for pronunciations in which the nasal either remains intact, i.e. does not affect the voicing value and nasality of the following stop, or coalesces with it, changing at the same time its voicing.

(8) Negation marker / min/ - verb

na $\min$ pist-ev-is

SBJV NEG believe-VBLZ-2SG

'you should not believe'

Table 1 summarizes the contexts in which PNV/NasCoal are enforced or blocked, depending on the item involved. ${ }^{2}$

Table 1. Application of PNV and NasCoal in function-lexical word strings

\begin{tabular}{lcccccc}
\hline & Compl & Det $_{\text {PL.GEN }}$ & Neg-min & Neg-ðen & Det $_{\text {SG.ACC }}$ & Cl $_{\text {sG.ACC }}$ \\
\hline Do not apply & $\checkmark$ & $\checkmark$ & $\checkmark$ & & & \\
Apply & & & $\checkmark$ & $\checkmark$ & $\checkmark$ & $\checkmark$ \\
\hline
\end{tabular}

2. The observed patterns of variation in the application of PNV/NasCoal are further buttressed by Kainada's (2009) experimental findings. In her study, most instances of voicing were identified in the context of negation ðen and the pronominal clitics tin, ton. The complementizer otan and the conditional particle an were found to be associated with mainly voiceless instances of stops. Finally, the stop following the negation $\min$ was equally identified as voiced and as voiceless (Kainada 2009: 113). 
At this point, we should call attention to yet another difference in word-final nasals between the two groups of function words. Nasals that are subject to PNV/ NasCoal also undergo deletion (Del) when the following word starts with a fricative. Interestingly, before vowel-initial words the nasals of both groups are faithfully realized. Table 2 illustrates the relevant environments and the outputs of various function words that end in nasals.

Table 2. Surface manifestation of $/ \mathrm{n} /$ in function words

\begin{tabular}{|c|c|c|c|c|}
\hline & & $\begin{array}{l}\text { Deletion } \\
\mathrm{C}_{[+ \text {cont }]}\end{array}$ & $\begin{array}{l}\mathrm{PNV} / \text { NasCoal } \\
\mathrm{C}_{[- \text {cont }]}\end{array}$ & $\begin{array}{l}\text { Faithful realization } \\
\ldots \mathrm{V}\end{array}$ \\
\hline a. & NEG & „ðе 'Өelo & „ðe mbi'stevo & „ðеn a'niyo ${ }^{3}$ \\
\hline b. & NEG & ${ }_{1} \mathrm{mi}^{\prime} \theta$ elis & ${ }_{1} \mathrm{mi}^{\mathrm{m}} \mathrm{bi}{ }^{\prime}$ stevis $/ \mathrm{min} \mathrm{p} \ldots$ & ${ }_{1}$ min a'nijis \\
\hline c. & DET.M.SG.ACC & to 'Aolo & to mbi'sto & ton 'anemo \\
\hline d. & CLITIC.F & ti 'ंelo & ti mbi'stevo & tin a'niyo \\
\hline e. & CLITIC.M & ton ${ }^{\prime} \theta \mathrm{elo}^{4}$ & to ${ }^{\mathrm{m}}$ bi'stevo & ton a'niyo \\
\hline f. & DET.M.PL.GEN & ton $\theta \mathrm{i}^{\prime}$ ron & ton pi'ston & ton a'nemon \\
\hline g. & COMP an & an 'Oelis & an pi'stevis & an a'nijis \\
\hline
\end{tabular}

As indicated in Table 2, coronal nasals in rows (a-d) undergo all three phonological processes and are realized faithfully only before vowels, as opposed to those in rows $(\mathrm{f}-\mathrm{g})$, which remain intact in all environments. The subtle difference in the strength of coronal nasals in certain forms has long been acknowledged in prescriptive grammars of Modern Greek (Triantafyllidis 1991 [/1941]; Holton et al. 2012: 23-25), where it is stated that word-final nasals, found in specific complementizers (otan, an, etc.), in the exponent of the PL.GEN form of the article and at the end position of content words, are 'stable', in the sense that they never delete before fricatives nor do they coalesce with stops. In contrast, the nasals of the forms in rows $(\mathrm{a}-\mathrm{d})$ are considered 'flimsy' because they are realized partially (as prenasalization) before stops and are eliminated before fricatives, with the exception of the masculine clitic form (see fn 4$){ }^{5}$

As mentioned in the Introduction (Section 1), we ascribe the difference between flimsy and stable /n/ to the nature of the nasal segment per se, rather than to pro-

3. Glosses: $a^{\prime}$ niy-o 'open-15G', a'nij-is 'open-2SG', 'anem-o 'wind-SG.ACC', $a^{\prime}$ nem-i 'spinning wheel-

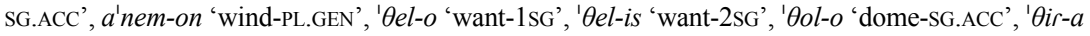
'gate-SG.ACC'.

4. The resistance of $/ \mathrm{n} /$ in the masculine form of the clitic to drop before a fricative is addressed in Section 4.

5. The difference between the two $/ \mathrm{n} /$ 's is deeply rooted in the Katharevousa (archaic vernacular) vs. Dhemotiki (modern vernacular) split. Final $/ \mathrm{n} /$ that deletes in Dhemotiki forms is preserved in the same forms of the Katharevousa vernacular, e.g., t-on pi'st-on 'the-SG.ACC believer-SG.ACC', 'ery-on 'task, work-N.SG.NOM/ACC'. 
sodic constituency. More specifically, flimsy /n/'s are argued to be segments of low activity level, a property that renders them susceptible to change. In the following section, we establish, on the basis of evidence from phonology proper as well as the morphosyntax-phonology interface, that function word-plus-lexical word strings are organized into the same prosodic constituent, namely the maximal phonological word (Itô \& Mester 2007, 2009 et seq.).

\section{The prosodic structure of function words}

Object clitics and functional elements (e.g., determiners, particles, complementizers, etc.) in Greek have been argued to prosodify into recursive prosodic words on the basis of both phonological and morphosyntactic criteria (Revithiadou \& Spyropoulos 2008). Given that there are open questions, both of theoretical and of empirical nature, regarding the exact number of categories in the Prosodic Hierarchy above the PW (Selkirk 1981; Hayes 1984, 1989; Nespor \& Vogel 1986, among others), Itô \& Mester (2007, 2009 et seq.) adopt a sparser hierarchy in which no additional categories intervene between the phonological phrase $(\varphi)$ and the PW. In their model, an extended prosodic word is formed when a word combines with additional material (e.g., function words) to form, by adjunction, a larger recursive structure, e.g. ${ }_{\omega}\left[\beta_{\omega}[\alpha]\right]$ (Itô \& Mester 2009: 135).

As illustrated in (9), the structure resulting from the larger (outermost) projection of $\omega$ is the maximal phonological word (henceforth $\omega^{\max }$ ), and the innermost subconstituent of $\omega$ is the minimal phonological word (henceforth $\omega^{\mathrm{min}}$ ). The additional layers that arise through prosodic adjunction to the existing prosodic categories do not constitute further distinct categories. ${ }^{6}$ By identifying maximal and minimal projections, Itô \& Mester's model acquires the flexibility required to descriptively distinguish different prosodic constituents without resorting to proliferation of prosodic categories. Of interest in this article is the $\omega^{\max }$ constituent, which constitutes the main domain for the prosodic organization of function word-plus-lexical word constructions.

Prosodic adjunction at the PW

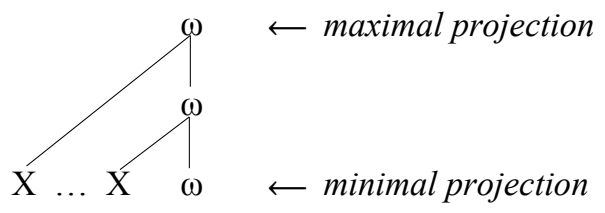

6. For Itô \& Mester (2007, 2009), each layer can have its own restrictions and phonological processes (or constraint hierarchies); in this sense, therefore, the projected word is not exactly recursive in the strict sense of the term. Kabak \& Revithiadou (2009) claim that the outermost layer may inherit rhythmic and other properties of the innermost one, but in an optional fashion. 


\subsection{The phonological argument}

A solid phonological argument for identifying PW-boundaries in Greek is glide strengthening (Baltazani et al. 2016), a wide-spread process whereby the glide $/ \mathrm{j} /$ undergoes fortition in onset position, i.e. changes in manner of articulation from an approximant to a fricative, e.g. /peð-j-a/ [pe'ðja] 'child-TH-PL.NOM', /rolo-j-a/ [ro'loja] 'watch-TH-PL.NOM. The process also affects word-initial high front vowels at hiatus contexts, e.g. /iatr-os/ [ja'tros] 'doctor-SG.NOM', /ial-j/ [ja'li] 'glass-TH. SG.NOM' (for the relation between the vowel $/ \mathrm{i} /$ and the glide $/ \mathrm{j} /$, see Baltazani \& Topintzi 2012; Apostolopoulou 2018, and references therein). As shown by the following example, the change of $/ \mathrm{j}, \mathrm{i} /$ into a fricative is blocked between a determiner and the following noun, suggesting that the relevant functional element falls outside the innermost PW:
(10) $/ \mathrm{i}$
the.F.SG.NOM Anna.SG.NOM
${ }_{\omega}^{\max }\left[\mathbf{i}_{\omega}[\right.$ 'ana $\left.]\right] \sim{ }_{\omega}^{\max }\left[\mathbf{j}_{\omega}\left[{ }^{\prime} \mathbf{a n a}\right]\right] /{ }_{\omega}{ }_{\omega}\left[j^{\prime} \mathbf{a n a}\right]$
'(det) Anna'

Further support for the prosodization of function words outside the PW is provided by syllabification and, in particular, the blocking of syllabification of the final consonant of a function word with vocalic material of a following lexical word. In (11), the final sibilant of the singular genitive form of the definite determiner, i.e. /tis/, does not syllabify as onset with the following vowel. In contrast, syllabication is not blocked across morphological boundaries or between a host and its clitic within the PW, e.g. /pros-eðaf-is-i/ ${ }_{\omega}$ [pro.se'ðafi.si] PRFX-land-NMLZ-SG.NOM 'landing', /ðos-e to/ ['ðo.sto] give-2sG.IMP it 'give it'.

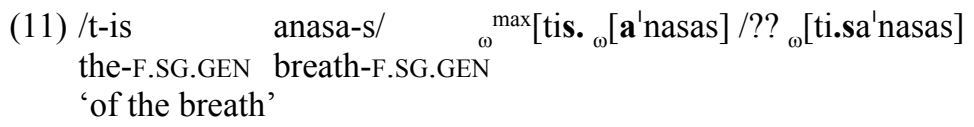

The last piece of evidence comes from stress; secondary stress prominence may optionally develop at the left edge of a $\omega^{\text {max }}$ suggesting the presence of a post-lexical foot, as shown in (12). Secondary stress in Greek is strictly prohibited within the PW, regardless of its length, e.g., /trom-o-krat-ik-os/ ${ }_{0}$ [tromokrati'kos] 'terrorist', /markaðor-os/ ${ }_{\omega}\left[\right.$ marka'ðoros] 'marker', but it is allowed within the $\omega^{\max }$. For instance, secondary stress may develop in stem-word compound formations, e.g., ${ }_{\omega}^{\max }\left[(\mathrm{pa} \hat{\mathrm{po}})_{\omega}\right.$ [marka'ðoros]] 'lousy marker', even when they are relatively short, e.g. ${ }_{\omega}^{\max }\left[(\text { para })_{\omega}[\right.$ 'vrexo $\left.]\right]$ 'pour down too much water-1SG'.
(12) /na t-a
SUBJV CL.3-N.PL.ACC
mayir-ev-i/
cook-VBLZ-3sG
${ }_{\omega}^{\max }\left[\left(\right.\right.$, na ta) ${ }_{\omega}[$ maji'revi $\left.]\right]$
'to be cooking them' 


\subsection{The syntactic argument}

In her seminal article on the prosodic word, Selkirk (1995: 458-460) embraces the morphosyntactic argument - next to the phonological one - in identifying phonological wordhood. Although the interface does not need to derive isomorphic structures, in this section we show that the extended PW for the prosodization of function words in Greek is in total agreement with the mode in which the relevant strings are syntactically processed. ${ }^{7}$

According to a long line of research within the generative framework (e.g., Chomsky 2001; Marantz 2007), the syntactic derivation proceeds in a cyclic fashion: Spell-Out does not take place at a single point of the derivation, but applies cyclically, every time a phase-defining head is introduced into the structure. Adopting a Distributed Morphology analysis of verb morphosyntax (Halle \& Marantz 1993), we take the standard view that C is a phase-defining head (e.g., Chomsky 2001) and, moreover, assume that there is a phase boundary between $\mathrm{C}$ and its complement (see Svenonius 2004 for various approaches on this issue). This entails that $\mathrm{C}$ is not spelled-out in the same phase with its complement and, consequently, the phonological processing of the vocabulary item that realizes the $\mathrm{C}$ head takes place after the phonological processing of the complement of $\mathrm{C}$ is complete. The bracketed structure in (13) (e.g., Philippaki-Warburton 1998; Philippaki-Warburton \& Spyropoulos 1999) is informative in this respect: complementizers such as pos/oti 'that', otan 'when' and an 'if' are phonologically processed in a different phase compared to the subjunctive marker $n a$, the negation markers ðen and $\mathrm{min}$, and the verb form, i.e. a complex T/Agr head formed via head movement (see Embick 2010):

$$
\begin{aligned}
& \text { Greek clause structure }
\end{aligned}
$$

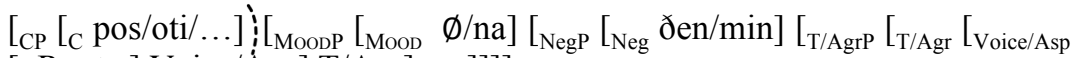

$$
\begin{aligned}
& {\left[{ }_{v} \text { Root } v\right. \text { ] Voice/Äsp] T/Agr] ... ]]]] }}
\end{aligned}
$$

Given the structure in (13), in a phrase like [('ipe) pos eti'mazi] '(s/he said) that $\mathrm{s} /$ he is preparing, pos is phonologically computed separately from the rest of the clause; hence, it cannot interact with the phonological material that embodies the verbal form [eti'mazi] and is prosodically parsed as an adjunct yielding an extended

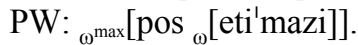

On the other hand, given that the subjunctive marker $n a$ and the verb form are processed during the same PF cycle, they are expected to form a single PW. Therefore, in a phrase like [('Өeli) na mas eti'mazi] '( $\mathrm{s} / \mathrm{he}$ wants) to prepare for us', the proposed analysis predicts that re-syllabification between the clitic mas and the

7. Selkirk (2011) proposes that prosodic boundaries may be present in positions predicted by the theory of syntax-prosody mapping, even when there is no overt phonological or phonetic evidence for their existence. For an informative discussion on aspects of the syntax-phonology interface, see, e.g., Selkirk (2000, 2011), Bonet et al. (2019), Bennett \& Elfner (2019); see also Dobashi (2003), Ishihara (2007), among others, for proposals on the mapping of Spell-Out domains to prosodic constituents. 
verb-initial vowel should take place. However, instead of the expected output ${ }_{\omega}[\mathrm{na}$. ma.seti'mazi], we get a recursive structure with an internal prosodic boundary and optional secondary stress on $n a:{ }_{\omega^{\max }\left[{ }_{1} \text { namas }\right.}{ }_{\omega}$ [eti'mazi]]. We claim that, in this case, the boundary does not result from cyclic Spell-Out but rather from the presence of a complex head, an M-Word (à la Embick 2010) in the structure, which translates into a prosodic boundary during phonological computation under the pressure of the alignment constraint ALIGN(M-word, L/R; PW, L/R).

The presence of a syntactic boundary that marks the launch of a Spell-Out cycle also explains the prosodic structure of DPs, which have been claimed to be cyclic domains (Svenonius 2004; Heck et al. 2009, among others). In particular, if we take determiners to be spelled-out separately from their complements, as we did for complementizers, then it follows that a definite article cannot belong to the same PW with the following noun. For example, in the DP [tis a'nasas] 'of the breath', the definite article $t$-is 'the-F.SG.GEN' is prosodized as an adjunct to the noun [a'nasas]: ${ }_{\omega}^{\max }\left[\right.$ tis ${ }_{\omega}\left[\mathrm{a}^{\prime}\right.$ nasas] $]$.

To sum up, we have provided phonology internal and external evidence in support of the presence of a boundary between (a string of) function words and verbal/ nominal forms, which stems either from cyclic Spell-Out or from the presence of an M-Word in the structure. In the next section we move on to laying out the key elements of our analysis and developing the grammar of stable and flimsy $/ \mathrm{n} /$ 's.

\section{A Gradient Harmonic Grammar account of flimsy and stable /n/}

\subsection{The underlying representation of flimsy and stable $\mathrm{l} / \textrm{ }$}

In order to account for the variant behavior of final $/ \mathrm{n} /$ in Greek, we put forward the claim that there exist nasals with different degree of strength so that the stronger ones are not susceptible to partial (or even complete) deletion. Drawing on Smolensky \& Goldrick (2016) and related work (e.g., Rosen 2016; Faust \& Smolensky 2017), we formalize these differences in the degree of strength of each nasal by means of Gradient Symbolic Representations, i.e. representations annotated with a specific numerical value called activity level (AL) that ranges from 0 to $1 .^{8} \mathrm{An}$ element with $\mathrm{AL}$ equal to 1 is strong enough to be pronounced and also to resist deletion or other types of phonological reduction. In contrast, an element with AL below 1 is only partially active; that is to say, it will be realized only if it is provided with epenthetic activity during phonological computation, or else, if it merges with another segment.

Based on the above, we posit that the default case is for the root node of a nasal $/ \mathrm{n} /$ in lexical and function words to be strong, i.e. to have an AL 1 (e.g., $/$ t-on $/$ 'the-PL.GEN', /otan $/$ ' 'when', / $\mathrm{an}_{1} /$ ' if'). Nevertheless, in a handful of function words there exist word-final nasals with an activity lower than 1 . This activity ranges from 0.5. to 0.7 depending on the item: $/ \mathrm{den}_{0.5} /{ }^{\prime} \mathrm{NEG}$ '; $/ \mathrm{t}-\mathrm{on}_{0.5} /, / \mathrm{t}-\mathrm{in}_{0.5} /$ 'the-M/F. ACC.SG'; $/$ t-in ${ }_{0.5} /{ }^{\text {'CL.3-F.SG.ACC'; } / \text { t-on }} 0.7$ ' 'CL.3-M.SG.ACC'. Moreover, we postulate

8. The activity value of a phonological element is indicated with a subscript number at its right side. 
two different allomorphs for the negation marker $/ \mathrm{min} /: / \mathrm{min}_{1} /$ and $/ \min _{0.6} /$. In the former, $/ \mathrm{n}_{1} /$ is adequately strong to surface intact in any environment, e.g. ${ }_{1} \mathrm{~min}$ 'treçis] 'don't run', [, min 'fijis] 'don't leave', as opposed to the latter, where $/ \mathrm{n}_{0.6}$ ' is forced either to coalesce or to delete, e.g. [ $\mathrm{mi}^{\prime}$ 'ndreçis], [ ${ }_{1} \mathrm{mi}$ 'fijis]. The two allomorphs stand in free variation, which explains the attested (inter- and intraspeaker) variation.

\subsection{Phonological computation: Gradient Harmonic Grammar}

The upside of numerically annotated representations is that they allow us to express variance in the enforcement of phonological processes such as PNV/NasCoal and Del in the Greek data at hand. However, gradient representations of phonological inputs alone cannot derive the attested patterns. We are therefore in need of a weighted constraint system that can compute gradient inputs and generate various phonological patterns. Such a model is offered by Gradient Harmonic Grammar (GHG, Smolensky \& Goldrick 2016). GHG is a constraint-based grammar of the same Gen-cum-Eval architecture as Optimality Theory (Prince \& Smolensky 1993; McCarthy \& Prince 1993, 1995), in which constraints, instead of being ranked, are numerically weighted as in Harmonic Grammar (Legendre et al. 1990; see also Smolensky \& Legendre 2006; Pater 2009, among others).

In a weighted constraint system, the penalty score for each constraint results by multiplying the number of violations incurred by a given candidate output with the weight $(\mathrm{w})$ of the constraint (displayed as a positive integer below the constraint in the tableau). Because violations constitute penalties, they are indicated with negative integers in the respective cell of the tableau ( $-\mathrm{n}$ for $n$ number of violations $\times \mathrm{w}$ ). In non-probabilistic versions of GHG, the winner is the candidate with the lowest penalty score in total or, more accurately, the candidate with the highest Harmony $(\mathrm{H})$ (where 'Harmony' is the sum of all individual penalty scores indicated for each candidate in the rightmost column of the tableau). It becomes clear that the contribution of each constraint to the $\mathrm{H}$ score of a candidate is crucial for the chances of this particular candidate to be selected as the optimum of a given phonological computation.

The main point of difference between GHG and other Harmonic Grammar models is that the weighted constraint system operates on activity-annotated inputs. As a consequence, any difference in the AL of the input has an effect on the penalty value induced by a faithful constraint. In particular, DEP penalizes outputs that have epenthesized activity from Gen; its violation is proportional to the amount of activity that is added in order for a weak segment to reach output activity 1. For example, let us assume that a hypothetical candidate $\left[n_{1}\right]$ realizes the weak input segment / $\mathrm{n}_{0.3} /$. To do so, it needs an amount of additional activity, i.e., 0.7 . The penalty score of the inserted activity is calculated by multiplying the 0.7 epenthetic activity with the constraint weight, say, $w 2(0.7 \times 2=-1.4)$. Likewise, the violation of MAX is also proportional to the underlying activity of a segment that does not make it to the surface. For instance, a candidate output $\left[\mathrm{n}_{0}\right]$ (of zero activity) that does not realize the input AL $0.3\left(/ \mathrm{n}_{0.3} /\right)$ causes a penalty of MAX that equals the weight of the constraint, i.e. 3 , times the lost activity, i.e., $(-0.3 \times 3=)-0.9$. 
The faithfulness constraints that penalize insertion and deletion of activity of the segmental root node, and their respective weights, are formulated in (14). A candidate output, such as $\left[\operatorname{ton}_{1}\right]$ for the clitic $/ \operatorname{ton}_{0.7} /$, for instance, yields a -10.5 $(-0.3 \times 35)$ penalty of DEP- $\bullet$. Similarly, an output with a deleted /n/, [ton 0 , causes $\mathrm{a}-14$ penalty of $\mathrm{MAX}-\bullet(-0.7 \times 20)$.

(14) a. DEP-• (w: 35): Assign a violation for any amount of activity of a segmental root node in the output that has no correspondent amount of underlying activity in the input (Smolensky \& Goldrick 2016).

b. MAX-• ( $w: 20)$ : Assign a violation for any amount of underlying activity of a segmental root node that has no correspondent amount of activity in the output (Faust \& Smolensky 2017).

The rest of the constraints that are relevant to our analysis are listed in (15). All are quite straightforward with the exception possibly of (15c), which essentially penalizes feature spreading, as in the case of post-nasal voicing assimilation, e.g., [nd] $</ \mathrm{n}$ t/ or place assimilation, e.g. [mp] $</ \mathrm{n} \mathrm{p} /$, and so on. The faithfulness constraint in (15f) represents many individual constraints with different weight values each (MAx[+vd] (w: 18), MAx[-vd] (w: 10), MAx[+nasal] (w: 18), MAx[COR] $(w: 4))$ and in general penalizes the deletion of feature activity; in this article the relevant features are all taken to have AL 1.

(15) a. *NFriC ( $w: 40)$ : Assign a violation to any post-nasal fricative.

b. ${ }^{*} \mathrm{NC}(w: 15)$ : Assign a violation to any post-nasal voiceless stop (Pater 1996).

c. $*_{\bullet}[\mathrm{F}] \bullet(w: 10)$ : Assign a violation to any feature node that is associated with more than one $\bullet$-nodes.

d. UNIFORMITY ( $w: 5)$ : Assign a violation for any element in the output that has multiple correspondents in the input (McCarthy \& Prince 1995).

e. CRispEdge[PW] ( $w$ : 6): Assign a violation for any crossing of PW-boundaries (Itô \& Mester 1994).

f. Max[F]: Assign a violation for any amount of underlying activity of $[\mathrm{F}]$ that has no correspondent amount of activity in the output.

Let us take a closer look at how the above constraints evaluate an input with a low activity nasal, $/ \mathrm{n}_{\mathrm{AL}}<1 /$, followed by a $/ \mathrm{t}_{1} /$-initial noun under three scenarios: coalescence and post-nasal voicing (16a), deletion (16b) and faithful realization (16c) of the nasal. As indicated in the bottom row, each scenario results in an output representation that causes the violation of a set of constraints. The choice among the three outputs is determined by both the weight of the violated constraints and the input activity value of the nasal. 
(16)

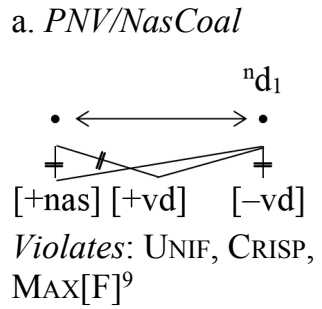

b. Del

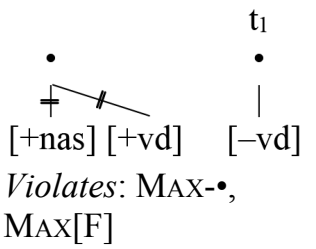

c. Faithful realization

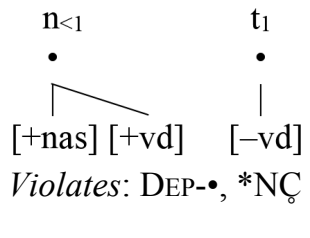

The following two tableaux demonstrate the difference between the PL.GEN determiner $/ \mathrm{t}$-on $/$ and the SG.ACC determiner $/ \mathrm{t}-\mathrm{on}_{0.5} /$ in the environment of a voiceless stop (e.g., /t/t). The assumed prosodic structure is the same, namely a $\omega^{\max }$. What differs is the input activity value of the final nasal. As shown in (17), a strong nasal is not subject to deletion nor to featural interaction with the neighboring stop. The faithful candidate (17b) has a lower penalty score compared to all others and, crucially, (17a), which undergoes PNV and NasCoal.

\begin{tabular}{|c|c|c|c|c|c|c|c|c|c|c|c|}
\hline \multirow[t]{2}{*}{$\begin{array}{l}(17) \\
/ \mathrm{t}-\mathrm{on}_{1 \mathrm{PL}, \mathrm{GEN}} \\
\mathrm{t}_{1} \ldots /\end{array}$} & DEP-• & MAX-• & $\begin{array}{c}\text { MAX } \\
{[+ \text { nas }]}\end{array}$ & $\begin{array}{l}\text { MaX } \\
{[+\mathrm{vd}]}\end{array}$ & $\begin{array}{l}\text { MAX } \\
{[\mathrm{COR}]}\end{array}$ & $\begin{array}{l}\mathrm{MAX} \\
{[-\mathrm{vd}]}\end{array}$ & *NÇ & $*_{\bullet}[\mathrm{F}] \bullet$ & UNIF & CRISP & \multirow[t]{2}{*}{$\mathrm{H}$} \\
\hline & 35 & 20 & 18 & 18 & 4 & 10 & 15 & 10 & 5 & 6 & \\
\hline a. $\left[\right.$ to $\left.\left[{ }^{\mathrm{n}} \mathrm{d}_{1} \ldots\right]\right]$ & & & & & & -1 & & & -1 & -1 & -21 \\
\hline b. $\left[\operatorname{ton}_{1}\left[\mathrm{t}_{1} \ldots\right]\right]$ & & & & & & & -1 & & & & -15 \\
\hline c. $\left[\operatorname{ton}_{1}\left[\mathrm{~d}_{1} \ldots\right]\right]$ & & & & & & -1 & & -1 & & -1 & -26 \\
\hline d. $\left[\operatorname{ton}_{0}\left[\mathrm{t}_{1} \ldots\right]\right]$ & & -1 & -1 & -1 & -1 & & & & & & -60 \\
\hline e. $\left[\operatorname{ton}_{0}\left[\mathrm{~d}_{1} \ldots\right]\right]$ & & -1 & -1 & -1 & -1 & -1 & & -1 & & -1 & -86 \\
\hline
\end{tabular}

The outcome of the tableau in (17) contrasts sharply with the output of the tableau in (18) where the input function word has a nasal of 0.5 activity. In this case, the faithful realization of the nasal entails insertion of extra activity which proves costly for the grammar given the weight of DEP-•. Coalescence with the following stop (18a) is preferred to total deletion of the low-activity nasal (18d) in this grammar because nasality and voicing are both preserved. Accumulation of penalties from the violation of the remainder constraints of the grammar eliminates all outputs but the coalesced one in (18a), which is the optimum.

9. In this case, DEP-• is not violated, given that no additional activity is required for the realization of the segment that results from coalescence. MAX-• is not violated either because both root nodes are realized. 


\begin{tabular}{|c|c|c|c|c|c|c|c|c|c|c|c|}
\hline \multirow[t]{2}{*}{\begin{tabular}{|l|}
$(18)$ \\
$/ \mathrm{t}-\mathrm{on}_{0.5 \mathrm{SG} . \mathrm{ACC}} \mathrm{t}_{1} \ldots /$
\end{tabular}} & DEP-• & MAX-• & $\begin{array}{c}\text { MAX } \\
{[+ \text { nas }]}\end{array}$ & $\begin{array}{l}\text { Max } \\
{[+\mathrm{vd}]}\end{array}$ & $\begin{array}{l}\text { MAX } \\
{[\mathrm{COR}]}\end{array}$ & $\begin{array}{l}\text { Max } \\
{[-\mathrm{vd}]}\end{array}$ & *NÇ & $* \bullet[\mathrm{F}] \bullet$ & UNIF & CRISP & \multirow[t]{2}{*}{$\mathrm{H}$} \\
\hline & 35 & 20 & 18 & 18 & 4 & 10 & 15 & 10 & 5 & 6 & \\
\hline a. $\left[\right.$ to $\left.\left[{ }^{\mathrm{n}} \mathrm{d}_{1} \ldots\right]\right]$ & & & & & & -1 & & & -1 & -1 & -21 \\
\hline b. $\left[\operatorname{ton}_{1}\left[\mathrm{t}_{1} \ldots\right]\right]$ & -0.5 & & & & & & -1 & & & & -32.5 \\
\hline c. $\left[\operatorname{ton}_{1}\left[\mathrm{~d}_{1} \ldots\right]\right]$ & -0.5 & & & & & -1 & & -1 & & -1 & -43.5 \\
\hline d. $\left[\operatorname{ton}_{0}\left[\mathrm{t}_{1} \ldots\right]\right]$ & & -0.5 & -1 & -1 & -1 & & & & & & -50 \\
\hline e. $\left[\operatorname{ton}_{0}\left[\mathrm{~d}_{1} \ldots\right]\right]$ & & -0.5 & -1 & -1 & -1 & -1 & & -1 & & -1 & -76 \\
\hline
\end{tabular}

One may wonder whether under the proposed analysis all nasals at the lexical level should be taken to be of low activity, given the obligatory application of

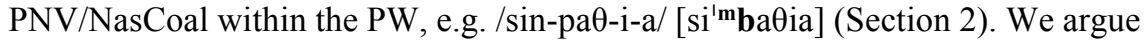
that this is not the case; all input coronal nasals in lexical words standardly have AL 1. The obligatoriness of both processes within the PW is associated with a scaling factor $(s)$, which targets the markedness constraint $* \mathrm{NC}$ and adjusts the constraint penalty according to the prosodic environment $\left(s 2=\omega, s 1=\omega^{\max }\right)$ in which the nasal occurs (Hsu 2019). More specifically, the *NC violations are scaled according to the size of the smallest prosodic constituent $(\omega)$ in which the nasal occurs. Essentially, scaling doubles the weight of $* \mathrm{NC}(w: 15)$ increasing its penalizing effect $(-(1 \times s 2 \times w 15)=-30)$ and reinforcing PNV/NasCoal within the innermost PW.

Interestingly, outputs with flimsy and stable nasals converge before a vowel-initial noun where both types of nasals are faithfully realized. This behavior is of course anticipated for $/ \mathrm{n}_{1} /$ but not for $/ \mathrm{n}_{0.5} /$. As illustrated by the tableau in (19), in the absence of a suitable host, i.e. a following stop, a partially active nasal has no other choice than to be pronounced. Crossing the prosodic boundaries (19b) or deleting the segment and all of its features (19c) turn out to be less economical options than charging the nasal with epenthetic activity (19a).

\begin{tabular}{|c|c|c|c|c|c|c|c|}
\hline \multirow{2}{*}{\begin{tabular}{|l|}
$(19)$ \\
$/ \mathrm{t}-\mathrm{on}_{0.5 \mathrm{SG} . \mathrm{ACC}} \mathrm{a}_{1} \ldots /$ \\
\end{tabular}} & DEP-• & MAX-• & MAx [+nas $]$ & $\operatorname{MAx}[+\mathrm{vd}]$ & $\operatorname{MAX}[\mathrm{COR}]$ & CRISP & \multirow[t]{2}{*}{$\mathrm{H}$} \\
\hline & 35 & 20 & 18 & 18 & 4 & 6 & \\
\hline a. $\left[\operatorname{ton}_{1}\left[\mathrm{a}_{1} \ldots\right]\right]$ & -0.5 & & & & & & -17.5 \\
\hline b. $\left[\right.$ to $\left.\left[\mathrm{n}_{1} \mathrm{a}_{1} \ldots\right]\right]$ & -0.5 & & & & & -1 & -23.5 \\
\hline c. $\left[\operatorname{ton}_{0}\left[\mathrm{a}_{1} \ldots\right]\right]$ & & -0.5 & -1 & -1 & -1 & & -50 \\
\hline
\end{tabular}

Finally, as mentioned in Section 2 (Table 2, fn 4), the /n/ of the M.SG.ACC clitic, unlike the same segment in the M.SG.ACC form of the determiner, does not delete before a fricative. We attribute this difference to the slightly higher strength of $/ \mathrm{n} /$ in the exponent of the pronoun, i.e. $/ \mathrm{n}_{0.7} /$. This slightly higher activity is sufficient to save the nasal from deletion in the respective environment, as illustrated by the tableaux in (20) and (21). 


\begin{tabular}{|c|c|c|c|c|c|c|c|}
\hline \multirow{2}{*}{$\begin{array}{l}(20) \\
/ \mathrm{t}-\mathrm{On}_{0.7 \mathrm{CL}} \theta_{1} \ldots /\end{array}$} & DEP-• & MAX-• & Max [+nas $]$ & $\operatorname{MAx}[+\mathrm{vd}]$ & $\operatorname{MAX}[\mathrm{COR}]$ & *NFRIC & \multirow[t]{2}{*}{$\mathrm{H}$} \\
\hline & 35 & 20 & 18 & 18 & 4 & 40 & \\
\hline a. $\left[\operatorname{ton}_{1}\left[\theta_{1} \ldots\right]\right]$ & -0.3 & & & & & -1 & -50.5 \\
\hline b. $\left[\operatorname{ton}_{0}\left[\theta_{1} \ldots\right]\right]$ & & -0.7 & -1 & -1 & -1 & & -54 \\
\hline
\end{tabular}

\begin{tabular}{|c|c|c|c|c|c|c|c|}
\hline \multirow{2}{*}{$\begin{array}{l}(21) \\
/ \mathrm{t}-\mathrm{on}_{0.5 \mathrm{DET}} \theta_{1} \ldots /\end{array}$} & DEP-• & MAX-• & Max [+nas $]$ & $\operatorname{Max}[+\mathrm{vd}]$ & $\operatorname{MAX}[\mathrm{COR}]$ & *NFRIC & \multirow[t]{2}{*}{$\mathrm{H}$} \\
\hline & 35 & 20 & 18 & 18 & 4 & 40 & \\
\hline a. $\left[\operatorname{ton}_{1}\left[\theta_{1} \ldots\right]\right]$ & -0.5 & & & & & -1 & -57.5 \\
\hline b. $\left[\operatorname{ton}_{0}\left[\theta_{1} \ldots\right]\right]$ & & -0.5 & -1 & -1 & -1 & & -50 \\
\hline
\end{tabular}

To conclude, in this section we posited two classes of coronal nasals in function words, those with AL below 1 and those with AL 1, and showed that only the former nasals are subject to PNV/NasCoal before a stop and deletion before a fricative. We have also demonstrated that, by fine-tuning constraint weights and input activities, GHG can formally express detailed distinctions in the patterning of function words within the same phonological constituent, i.e. the $\omega^{\max }$. In the next section, we briefly discuss some alternatives to our analysis.

\section{Exploring some alternatives}

One may explain the readiness of flimsy nasals to coalesce or delete by manipulating the weight of certain constraints so that they do not have the same effects across words. This can be accomplished by introducing lexical scaling, next to scaling associated with the type of prosodic structure (see discussion in Section 4.2 on the obligatory application of PNV/NasCoal within the PW). More precisely, the exponent $t$-on $n_{\mathrm{SG} . \mathrm{ACC}}$ could be taken to be lexically associated with a relatively high scale value, say, $s 2$ that targets the constraint *NC ( $w: 15)$ doubling its weight $(s 2 \times$ $w 15)$ (see Gouskova \& Linzen 2015). When an input structure contains the relevant indexed form, the violation of $* \mathrm{NC}$ is scaled up, enforcing coalescence outside the innermost PW and at the higher layer of the PW. Although this approach can possibly explain the set of data under examination, it cannot express the essence of the process, which is the resilience of the nasal - and not of the whole word - to coalesce and delete.

Finally, those who are less favorable to the idea of assigning numerical indexes to input segments might find more advantageous an analysis that represents flimsy /n/'s as floating elements, as opposed to stable ones, which are associated to the skeleton. Under this approach, only floating nasals are subject to change: they link to stops, producing pre-nasalized voiced stops, but delete before fricatives. The problem with this analysis is that it identifies only two types of segments, leaving unaccounted for the gradient patterns discussed in Section 4, such as, for example, the preservation of a nasal before fricatives in the case of the M.SG.ACC form of the clitic but not in the M.SG.ACC form of the determiner. 


\section{Conclusions}

In this article we have shown that gradient symbolic representations in a weighted constraint grammar can provide a promising avenue for constructing a parsimonious analysis of lexical variability without having to resort to proliferation of prosodic constituents. More specifically, we have argued that the extended PW, i.e. $\omega^{\text {max }}$, serves as the constituent for the prosodic organization of all function words in Greek, and attributed the inconsistent realization of word-final nasals to underlying strength contrasts. By positing segments with different AL values, e.g. $/ \mathrm{n}_{1} /, / \mathrm{n}_{0.7} /$, $/ \mathrm{n}_{0.6} /, / \mathrm{n}_{0.5} /$, at various phonological environments but within the same prosodic constituent, the proposed analysis succeeds in capturing fine-grained distinctions in the realization patterns of a word-final nasal. More importantly, it identifies the nasal, and not the whole function word, as the controlling factor in the selection of gradient outputs. An added gain is that our analysis is consistent with the diachronic development of final $/ \mathrm{n} /$ loss as this is still reflected in the split between the archaic and the modern vernacular (see fn 5).

Future research should unveil the factors that can additively contribute to the strength of a given segment. On the basis of Greek data, it is rather safe to infer that frequency and/or morphosyntactic markedness may play a role, given that nasals of lower strength are more likely to be associated with frequent lexical items or exponents of unmarked morphemes (e.g., SG and ACC, as opposed to PL and GEN respectively).

\section{References}

Apostolopoulou, Irini. 2018. Phonological Representation of Glide in Standard Greek: A Gradient Harmonic Grammar Approach. MA dissertation, A.U.Th.

Arvaniti, Amalia \& Joseph, Brian D. 1999. Variation in voiced stop prenasalization in Greek. Ohio State University Working Papers in Linguistics 52: 203-233.

Baltazani, Mary \& Topintzi, Nina. 2012. On some phonetic and phonological properties of the Greek glide. In Gavriilidou, Zoe, Efthymiou, Angeliki, Thomadaki, Evangelia \& Kambakis-Vougiouklis, Penelope (eds.). Proceedings of the 10th ICGL, 153-166. Komotini: Democritus University of Thrace.

Baltazani, Mary, Kainada, Evia, Revithiadou, Anthi \& Topintzi, Nina. 2016. Vocoiddriven processes: Palatalization and glide hardening in Greek and its dialects. Glossa: A Journal of General Linguistics 1(1): 23.

$<$ http://doi.org/10.5334/gjgl.108>

Bennett, Ryan \& Elfner, Emily. 2019. The Syntax-Prosody Interface. Annual Review of Linguistics 5(1). Annual Reviews: 151-171. $<$ https://doi.org/10.1146/annurev-linguistics-011718-012503>

Bonet, Eulàlia, Cheng, Lisa Lai-Shen, Downing, Laura J. \& Mascaró, Joan. 2019. (In) direct reference in the phonology-syntax interface under Phase Theory: A response to "Modular PIC" (D’Alessandro and Scheer 2015). Linguistic Inquiry 50(4): 751777.

$<$ https://doi.org/10.1162/ling_a_00324>

Booij, Geert. 1995. The Phonology of Dutch. Oxford: Clarendon Press. 
Booij, Geert. 1996. Cliticization as prosodic integration: The case of Dutch. The Linguistic Review 13: 219-242. $<$ https://doi.org/10.1515/tlir.1996.13.3-4.219>

Chomsky, Noam. 2001. Derivation by phase. In Michael Kenstowicz (ed.). Ken Hale. A Life in Language, 1-52. Cambridge, MA: Cambridge University Press.

Dobashi, Yoshihito. 2003. Phonological Phrasing and Syntactic Derivation. PhD dissertation., Linguistics, Cornell University.

Embick, David. 2010. Localism versus Globalism in Morphology and Phonology. Cambridge, MA: MIT Press.

Faust, Noam \& Smolensky, Paul. 2017. Activity as an Alternative to Autosegmental Association. Unpublished manuscript, Université Paris 8 \& John Hopkins University.

Gouskova, Maria \& Linzen, Tal. 2015. Morphological conditioning of phonological regularization. The Linguistic Review 32(3): 427-473.

$<$ https://doi.org/10.1515/tlr-2014-0027>

Halle, Morris \& Marantz, Alec. 1993. Distributed Morphology and the pieces of inflection. In Hale, Kenneth \& Keyser, Samuel Jay (eds.). The View from Building 20: Essays in Linguistics in Honor of Sylvain Bromberger, 111-176. Cambridge, MA: MIT Press.

Hayes, Bruce. 1984. The phonology of rhythm in English. Linguistic Inquiry 15(1): 33-74.

Hayes, Bruce. 1989. The prosodic hierarchy in meter. In Kiparsky, Paul \& Youmans, Gilbert (eds.). Rhythm and Meter, 201-260. Orlando, FL: Academic Press.

Heck, Fabian, Müller, Gereon \& Trommer, Jochen. 2009. A phase-based approach to Scandinavian definiteness marking. STUF 62(4): 258-268. $<$ https://doi.org/10.1524/stuf.2009.0020>

Holton, David, Mackridge, Peter, Philippaki-Warburton, Irene \& Spyropoulos, Vassilios. 2012. Greek: A Comprehensive Grammar. 2nd ed. London: Routledge.

Hsu, Brian. 2019. Exceptional prosodification effects revisited in Gradient Harmonic Grammar. Phonology 36(2): 225-263. $<$ https://doi.org/10.1017/S0952675719000125>

Inkelas, Sharon. 1990. Prosodic Constituency in the Lexicon. Outstanding Dissertations in Linguistics Series. New York: Garland Publishing Co.

Ishihara, Shinichiro. 2007. Major phrase, focus intonation, multiple Spell-Out. The Linguistic Review 24(2-3): 137-167.

$<$ https://doi.org/10.1515/TLR.2007.006>

Itô, Junko \& Mester, Armin. 1994. Reflections on CodaCond and Alignment. In Jason Merchant, Padgett, Jaye \& Walker, Rachel (eds.). Phonology at Santa Cruz [PASC] 3: 27-46. Linguistics Research Center, University of California, Santa Cruz.

Itô, Junko \& Mester, Armin. 2007. Prosodic adjunction in Japanese compounds. MIT Working Papers in Linguistics 55: Formal Approaches to Japanese Linguistics 4: 97-111.

Itô, Junko \& Mester, Armin. 2009. The extended prosodic word. In Kabak, Barış \& Grijzenhout, Janet (eds.). Phonological Domains: Universals and Derivations, 135194. The Hague: Mouton de Gruyter.

$<$ https://doi.org/10.1515/9783110217100.2.135> 
Kabak, Bariş \& Revithiadou, Anthi. 2009. An interface approach to prosodic word recursion. In Kabak, Barıș \& Grijzenhout, Janet (eds.). Phonological Domains: Universals and Derivations, 105-132. The Hague: Mouton de Gruyter. $<$ https://doi.org/10.1515/9783110217100.2.105>

Kainada, Evia. 2009. The Phonetic and Phonological Nature of Prosodic Boundaries: Evidence from Modern Greek. PhD dissertation, University of Edinburgh.

Kong, Eun Jong, Beckman, Mary E. \& Edwards, Jan. 2007. Fine-grained phonetics and acquisition of Greek voiced stops. In Proceedings of the 16th ICPhS, 865-868.

Legendre, Géraldine, Miyata, Yoshiro \& Smolensky, Paul. 1990. Harmonic Grammar A formal multi-level connectionist theory of linguistic well-formedness: Theoretical foundations. In Proceedings of the $12^{\text {th }}$ Conference of the Cognitive Science Society, 388-395. Cambridge, MA: Lawrence Erlbaum Associates.

Marantz, Alec. 2007. Phases and words. In Choe, Sook Hee (ed.). Phases in the Theory of Grammar, 191-222. Seoul: Dong-In Publishing.

McCarthy, John J. \& Prince, Alan S. 1993. Generalized Alignment. In Booij, Geert \& van Marle, Jaap (eds.). Yearbook of Morphology 1993, 79-153. Dordrecht: Kluwer.

McCarthy, John J. \& Prince, Alan S. 1995. Faithfulness and reduplicative identity. In Beckman, Jill, Walsh Dickey, Laura \& Urbanczyk, Suzanne (eds.). University of Massachusetts Occasional Papers in Linguistics 18: Papers in Optimality Theory, 249-384. GLSA, University of Massachusetts at Amherst.

Nespor, Marina \& Vogel, Irene. 1986. Prosodic Phonology. Dordrecht: Foris Publications.

Pater, Joe. 1996. *NC. Proceedings of the North East Linguistics Society 26: 227-239.

Pater, Joe. 2009. Weighted constraints in generative linguistics. Cognitive Science 33: 999-1035.

$<$ https://doi.org/10.1111/j.1551-6709.2009.01047.x>

Peperkamp, Sharon. 1997. Prosodic Words. PhD dissertation, HIL Dissertation Series 34 (HIL/University of Amsterdam). The Hague: Holland Academic Graphics.

Philippaki-Warburton, Irene. 1998. Functional categories and Modern Greek syntax. The Linguistic Review 15: 158-186.

$<$ https://doi.org/10.1515/tlir.1998.15.2-3.159>

Philippaki-Warburton, Irene \& Spyropoulos, Vassilios. 1999. On the boundaries of inflection and syntax: Greek pronominal clitics and particles. In Booij, Geert \& van Marle, Jaap (eds.). The Yearbook of Morphology 1998, 45-72. Dordrecht: Kluwer.

Prince, Alan \& Smolensky, Paul. 1993. Optimality Theory: Constraint Interaction in Generative Grammar. Technical Report CU-CS-696-95. RuCCS-TR-2.

Revithiadou, Anthi \& Spyropoulos, Vassilios. 2008. Greek object clitic pronouns: A typological survey of their grammatical properties. STUF 61: 39-53. $<$ https://doi.org/10.1524/stuf.2008.0005>

Rosen, Eric. 2016. Predicting the unpredictable: Capturing the apparent semi-regularity of rendaku voicing in Japanese through harmonic grammar. In Clem, Emily, Dawson, Virginia, Shen, Alice, Horan Skilton, Amalia, Bacon, Geoff, Cheng, Andrew \& Maier, Erik Hans (eds.). Proceedings of BLS 42, 235-249. Berkeley Linguistic Society.

Selkirk, Elizabeth O. 1981. On prosodic structure and its relation to syntactic structure. In Fretheim, Thorstein (ed.). Nordic Prosody II: Papers from a Symposium, 111140. Trondheim: TAPIR. 
Selkirk, Elizabeth O. 1995. Sentence prosody: Intonation, stress and phrasing. In Goldsmith, John (ed.). The Handbook of Phonological Theory, 550-569. Cambridge, MA: Blackwell.

Selkirk, Elizabeth O. 2000. The interaction of constraints on prosodic phrasing. In Horne, Merle (ed.). Prosody: Theory and Experiment: Studies Presented to Gösta Bruce, 231-261. Dordrecht: Kluwer.

Selkirk, Elisabeth O. 2011. The syntax-phonology interface. In Goldsmith, John, Riggle, Jason \& Yu, Alan C.L. The Handbook of Phonological Theory, 435-484. Malden, MA: Wiley-Blackwell.

$<$ https://doi.org/10.1002/9781444343069.ch14>

Smolensky, Paul \& Goldrick, Matthew. 2016. Gradient Symbolic Representations in Grammar: The Case of French Liaison. Unpublished manuscript, Johns Hopkins University \& Northwestern University. [ROA 1552]

Smolensky, Paul \& Legendre, Géraldine. 2006. The Harmonic Mind: From Neural Computation to Optimality-Theoretic Grammar. Cambridge, MA: MIT Press.

Svenonius, Peter. 2004. On the edge. In Adger, David, de Cat, Cécile \& Tsoulas, George (eds.). Peripheries: Syntactic Edges and Their Effects, 259-287. Dordrecht: Kluwer. $<$ https://doi.org/10.1007/1-4020-1910-6_11>

Triantafyllidis, Manolis. 1991 [1941]. Neoeliniki Grammatiki (tis Dimotikis) [Modern Greek Grammar (of the Demotic Variety)]. Thessaloniki: Institute of Modern Greek Studies.

Vigário Marina. 2003. The Prosodic Word in European Portuguese. Berlin: Mouton de Gruyter.

Vigário Marina. 2010. Prosodic structure between the prosodic word and the phonological phrase: Recursive nodes or an independent domain? The Linguistic Review 27: 485-530.

$<$ https://doi.org/10.1515/tlir.2010.017> 
